\title{
Correlation between the Resistive Index Values of Renal and Orbital Arteries
}

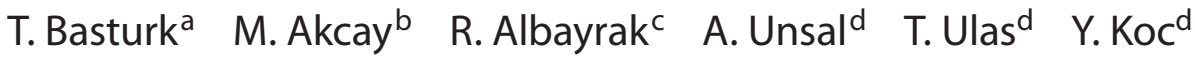 \\ Departments of ${ }^{a}$ Nephrology, ${ }^{b}$ Ophthalmology and ${ }^{\mathrm{c} R a d i o l o g y, ~ B a g c i l a r ~ R e s e a r c h ~ a n d ~ E d u c a t i o n ~ H o s p i t a l, ~ a n d ~}$ \\ ${ }^{\mathrm{d}}$ Department of Nephrology, Sisli Etfal Research and Education Hospital, Istanbul, Turkey
}

\section{Key Words}

Resistive index - Diabetic nephropathy $\cdot$ Diabetic

retinopathy $\cdot$ Doppler ultrasonography

\begin{abstract}
Background: Resistive index (RI) is an indirect measurement of blood flow resistance that can be used to evaluate vascular damage. Aims: The purpose of this study is to evaluate the association between RI values of orbital and intrarenal arteries by means of Doppler ultrasonography (US). Methods: We evaluated 103 diabetic patients. As a control group, 30 subjects were examined. The patients were divided into two groups. Group 1 consisted of patients with urinary albumin excretion (UAE) $<300 \mathrm{mg} /$ day and estimated glomerular filtration rate (eGFR) levels $>90 \mathrm{ml} / \mathrm{min}(\mathrm{n}=50)$; Group 2 had a UAE $>300 \mathrm{mg} /$ day and/or eGFR levels between 89 and $60 \mathrm{ml} /$ $\min (n=53)$. The association between RI values obtained with Doppler US of the ophthalmic artery, central retinal artery, posterior ciliary artery and intrarenal arteries were calculated. Results: Both orbital and intrarenal arterial RI values in Group 1 and Group 2 were higher than the control group $(p=0.001)$; furthermore, values were higher in Group 2 than in Group 1 ( $p=0.0004 / 0.029 / 0.036, p=0.016$, respectively). A positive correlation was found between orbital and intra-
\end{abstract}

renal arterial RI values in Group $2(r=0.475,0.285,0.363, p<$ 0.01 , respectively). Conclusion: Both orbital and renal arterial RI values were shown to be higher than the control group. Further, a trend towards higher RI values was observed with renal disease. RI may be useful as one of the markers for early diagnosis and follow-up of diabetic nephropathy and retinopathy.

Copyright $\odot 2012$ S. Karger AG, Basel

\section{Introduction}

Doppler ultrasonography (US) provides morphologic and vascular information noninvasively in various diseases [1]. The diagnostic validity of Doppler US in renal parenchymal disease is still under debate; however, recent studies have shown that the resistive index (RI) correlates with tubulointerstitial and vascular lesions [2]. Doppler US may also be used to evaluate orbital vascular flow velocities and characteristics [3].

The RI is a parameter for characterizing the arterial waveform with Doppler US [4]. In vitro and in vivo studies have shown that RI is related to vascular resistance [5]. Diabetes mellitus (DM) alters vascular resistance in the kidneys [6] and eyes [7]. The retinal microcirculation 
shares similar physiological and pathological characteristics with the renal microcirculation $[8,9]$. Previous studies have documented the strong association between intrarenal RI values and extrarenal markers of vascular stiffness, such as intima-media thickness of the femoral and carotid arteries [10].

The purpose of the present study is to evaluate the association between the ophthalmic artery (OA), central retinal artery (CRA), posterior ciliary artery (PCA) and intrarenal arterial RI by means of Doppler US in diabetic patients with and without kidney disease.

\section{Materials and Method}

\section{Patients}

The study population consisted of 103 patients with type 2 DM who were initially seen in the nephrology polyclinic from June 2009 to September 2010.

The diagnosis of DM was based on a previous history of diabetes (antidiabetic medication usage) or the American Diabetes Association criteria [11]. As a control group, 30 age- and sexmatched subjects were examined. The patients signed a written informed consent form to participate in study. The study was approved by the local ethics committee.

Diabetic patients were divided into two groups according to urinary albumin excretion (UAE) and glomerular filtration rate (GFR) levels as follows: Group 1 consisted of patients with UAE $<300 \mathrm{mg} /$ day and GFR $\geq 90 \mathrm{ml} / \mathrm{min}(\mathrm{n}=50)$, and Group 2 had a $\mathrm{UAE} \geq 300 \mathrm{mg} /$ day and/or GFR levels between 89 and $60 \mathrm{ml} / \mathrm{min}$ $(\mathrm{n}=53)$. The patients in both groups were divided again into two groups according to presence $(1 \mathrm{a}, 2 \mathrm{a})$ or absence of diabetic retinopathy $(1 b, 2 b)$.

None of the control subjects had proteinuria, renal insufficiency, DM, hypertension, cardiovascular disease, cerebrovascular disease or peripheral vascular disease. In each diabetic patient, 24-hour urine collections were performed in order to determine the level of UAE. Renal function was calculated using the Modification of Diet in Renal Disease estimated GFR formula [12] and was grouped according to the United States National Kidney Foundation guidelines for the diagnosis and classification of chronic kidney disease (CKD) [13].

Fundus examination was performed in all patients by a trained ophthalmologist using direct and indirect ophthalmoscopy through dilated pupils. The diabetic retinopathy stage was evaluated according to the Fukuda classification [14]. Patients with background retinopathy (A0, A1 and A2) were included in the study.

Hypertension was defined as one or more systolic blood pressure values $>140 \mathrm{~mm} \mathrm{Hg}$, diastolic blood pressure $>90 \mathrm{~mm} \mathrm{Hg}$ or use of any antihypertensive medication [15]. Blood pressure was measured three times with a standard mercury sphygmomanometer and a cuff around the arm. Subjects rested in the supine position for at least $10 \mathrm{~min}$ before blood pressure measurements, and the average of three measurements was documented.

All patients were receiving antihypertensive therapy. Monotherapy with a renin-angiotensin system inhibitor was used by 28 patients in Group 1 and 14 patients in Group 2. Combination ther- apy with a renin-angiotensin system inhibitor, calcium channel antagonist, $\alpha$-blocker and diuretic was used by 22 patients in Group 1 and by 39 patients in Group 2. BMI was calculated from height and weight measurements.

To exclude patients with nondiabetic or postrenal failure patients with microscopic or macroscopic hematuria or an abnormal urinary sediment, a past history of glomerulonephritis or nephroureterolithiasis, or dilated renal pelvis on real-time US were not included in the study. Patients who had severely atrophic kidney(s), either unilateral or bilateral, were also excluded from study because of poor imaging quality of blood flow with Doppler sonography and difficulty in detecting waveforms.

One eye (right eye, unless another ophthalmic pathology was present) was included from each patient. Eyes that had an ophthalmic condition that could interfere with the ophthalmic arteries, such as glaucoma, age-related macular degeneration, high myopia, etc., and those with laser photocoagulation or previous ophthalmic surgery were also excluded from the study.

\section{Biochemical Analysis}

Blood was drawn from patients after an overnight fast for the analysis of plasma levels of hemoglobin A1 (HbA1), serum creatinine, albumin and $\mathrm{HbAlc}$ using high-performance liquid chromatography. Serum creatinine and albumin were measured with an autoanalyzer. Urinary albumin was measured in 24-hour urine collections by immunoturbidimetry.

\section{Renal Doppler US}

A Hitachi EUB 515 scanner was used to determine blood flow measurements with a $3.5-\mathrm{MHz}$ convex transducer. Doppler US examination was performed with subjects in the supine position after they had rested for $15 \mathrm{~min}$. A wall filter was set to the minimum $(50 \mathrm{~Hz})$ and the sample volume was set at $2-5 \mathrm{~mm}$. RIs are measured in each kidney using the existing software (automated algorithm) capabilities of the scanner. After a proper velocity waveform was obtained, the mean RI was calculated from six measurements taken for each patient. Intrarenal RI values were obtained from intraparenchymal arteries of both kidneys, either the arcuate or interlobar. The mean RI value for each kidney was calculated from all measurements.

A mean RI value is obtained for each patient by averaging the two kidneys' mean RI values. All Doppler examinations were performed by the same examiner (blinded to renal status of the patients) to avoid interobserver variability. The RI was determined as follows: $\mathrm{RI}=(\mathrm{PSV}-\mathrm{EDV}) / \mathrm{PSV}$, in which PSV = peak systolic flow velocity and $\mathrm{EDV}=$ end-diastolic flow velocity.

The use of antihypertensive agents was not suspended before the RI measurement. None of the patients who were included in the study had a peak systolic velocity of the main renal artery over $180 \mathrm{~cm} / \mathrm{s}$ or had evidence of kidney atrophy ( $<8 \mathrm{~cm}$ length).

\section{Orbital Doppler US}

A Hitachi EUB 515 scanner was used to determine blood flow measurements. A 7.5-MHz linear transducer was used to measure $\mathrm{RI}$ in the OA, CRA and PCA. The same radiologist examined all patients and controls to avoid interobserver variability. The patients and the control group were examined in the supine position with the head tilted at an angle of about $30^{\circ}$ after 10 min of rest. The RI was calculated [(PSV - EDV)/PSV] by computer for each vessel measured. 
Table 1. Clinical characteristics of the diabetic patients

\begin{tabular}{lcc}
\hline & Min.-max. & Mean \pm SD \\
\hline Age, years & $34-77$ & $54.05 \pm 10.01$ \\
Diabetes duration, years & $1-20$ & $8.58 \pm 4.88$ \\
Hypertension duration, years & $1-20$ & $6.31 \pm 5.79$ \\
Systolic BP, mm Hg & $90-170$ & $128.54 \pm 16$ \\
Diastolic BP, mm Hg & $60-90$ & $76.49 \pm 7.17$ \\
BMI & $19.4-49.5$ & $30.3 \pm 5.3$ \\
UAE, mg/day & $54-8,466$ & $608.33 \pm 1,391.31$ \\
Estimated GFR, ml/min & $65-203$ & $111 \pm 44$ \\
HbA1c, \% & $5.50-16$ & $7.70 \pm 1.74$ \\
\hline & $\mathrm{n}$ & $\%$ \\
& & \\
\hline Gender & 60 & 37.3 \\
$\quad$ Male & 101 & 56.3 \\
$\quad$ Female & & 38.8 \\
CKD (-) & 26 & 61.2 \\
$\quad$ Retinopathy (+) & & \\
Retinopathy (-) & 41 & 37.3 \\
CKD (+) & & \\
Retinopathy (+) & 42 & \\
Retinopathy (-) & 25 & \\
\hline & & \\
\hline
\end{tabular}

Table 2. RI values of intrarenal and orbital arteries in control and diabetic patients

\begin{tabular}{llll}
\hline & $\begin{array}{l}\text { Group 1 } \\
(\mathrm{n}=50)\end{array}$ & $\begin{array}{l}\text { Controls } \\
(\mathrm{n}=30)\end{array}$ & $\begin{array}{l}\text { Group 2 } \\
(\mathrm{n}=53)\end{array}$ \\
\hline Intrarenal arteries RI & $0.65 \pm 0.06$ & $0.59 \pm 0.03$ & $0.71 \pm 0,06$ \\
OA RI & $0.73 \pm 0.06$ & $0.68 \pm 0.06$ & $0.77 \pm 0.08$ \\
CRA RI & $0.66 \pm 0.07$ & $0.63 \pm 0.09$ & $0.69 \pm 0.07$ \\
PCA RI & $0.72 \pm 0.06$ & $0.67 \pm 0.07$ & $0.74 \pm 0.06$ \\
\hline
\end{tabular}

\section{Statistical Analysis}

The NCSS (Number Cruncher Statistical System) 2007 and PASS (Power Analysis and Sample Size) 2008 statistical software (Utah, USA) programs were used for the statistical analysis. During the evaluation of the data obtained from the study, a Kolmogorov-Smirnov test was used for the comparisons of descriptive statistical methods (means, SD, frequency, rate) as well as conformity of the data to a normal distribution. Student's t test was used for the intergroup comparisons of parameters with normal distribution and a Mann-Whitney $U$ test was used for the intergroup comparisons of parameters without normal distribution. For the evaluation of correlations between intrarenal and orbital RI measurements, Pearson's correlation analysis was used. Linear regression analysis was used to examine the influence of orbital RI measurements on intrarenal measurements. A $\chi^{2}$ test was used for comparison of qualitative data. Significance was evaluated at a level of $\mathrm{p}<0.05$.

\section{Results}

Clinical data of the studied patients are shown in table 1.

\section{RI of Intrarenal Arteries in Control and Diabetic}

Patients

The mean intrarenal RI was $0.65 \pm 0.06$ in Group 1, $0.71 \pm 0.06$ in Group 2 and $0.59 \pm 0.03$ in the control group. Intrarenal RI values in Group 1 and Group 2 patients were significantly higher than in the control group $(\mathrm{p}<0.001)$. Intrarenal RI values in Group 2 patients were higher than in Group 1 ( $\mathrm{p}=0.016$; table 2).

There was a significant difference in age (50.85 \pm $8.34 / 58.25 \pm 10.46$ years, $\mathrm{p}=0.001)$, GFR (116.96 \pm $14.67 / 109.16 \pm 17.97 \mathrm{ml} / \mathrm{min}, \mathrm{p}=0.018)$ and UAE (182.59 $\pm 59.31 / 1,490.6 \pm 2,285.17 \mathrm{mg} /$ day, $\mathrm{p}=0.001)$ values in Group 1 compared to Group 2 (table 3).

The relationship between intrarenal RI values and GFR in Group 2 showed a negative correlation coefficient of $\mathrm{r}=-0.346, \mathrm{p}=0.023$. The relationship between intrarenal RI values, duration of diabetes and age in Group 2 showed a positive correlation coefficient of $r=0.362, p=$ 0.001 and $\mathrm{r}=0.323, \mathrm{p}=0.023$.

There was no correlation between RI values and clinical factors in Group 1 (table 4).

RI of Orbital Arteries in Control and Diabetic Patients

The mean OA, CRA and PCA RI values were $0.73 \pm$ $0.06,0.66 \pm 0.07$ and $0.72 \pm 0.06$ in Group $1,0.77 \pm$ $0.08,0.69 \pm 0.07$ and $0.74 \pm 0.06$ in Group 2, and 0.68 $\pm 0.06,0.63 \pm 0.09$ and $0.67 \pm 0.07$ in the control group. The mean OA, CRA and PCA RI were significantly increased in Group 2 compared to Group 1 ( $p=0.0004$, $0.029,0.036$, respectively), and the mean OA, CRA and PCA RI values were different between the diabetic groups and the control group ( $<<0.001$; table 2$)$.

The relationship between the RI value of OA, PCA and GFR in Group 2 showed a negative correlation coefficient of $\mathrm{r}=-0.279$ and $\mathrm{r}=-0.347, \mathrm{p}<0.05$. The relationship between OA, CRA and PCA RI values; duration of diabetes; and age in Group 2 showed a positive correlation coefficient of $\mathrm{r}=0.365,0.339,0.314, \mathrm{p}<0.01, \mathrm{r}=0.343,0.272$, 0.195 (respectively), $\mathrm{p}<0.05$. The relationship between the RI value of only OA and GFR in Group 1 showed a negative correlation coefficient of $\mathrm{r}=-0.279, \mathrm{p}<0.05$ (table 5).

\section{Relationship between Intrarenal and Orbital Arterial RI Values}

In all patients, intrarenal RI values are compared with RI values of OA, CRA and PCA. A positive correlation 
Table 3. Comparison of the clinical characteristics of control and diabetic subjects

\begin{tabular}{|c|c|c|c|c|}
\hline Gender, male/female & $26 / 41$ & $12 / 18$ & $24 / 43$ & NS \\
\hline Age, years & $50.8 \pm 8.3$ & $53.6 \pm 9.9$ & $58.2 \pm 10.5$ & NS \\
\hline BMI & $30.11 \pm 5.87$ & $30.53 \pm 5.41$ & $30.45 \pm 4.73$ & NS \\
\hline Diabetes duration, years & $7.6 \pm 4.7$ & - & $9.54 \pm 4.9$ & 0.039 \\
\hline Hypertension duration, years & $6.5 \pm 5.8$ & - & $6.2 \pm 5.9$ & NS \\
\hline $\mathrm{HbA} 1 \mathrm{c}, \%$ & $7.58 \pm 1.21$ & $6.41 \pm 0.28$ & $8.15 \pm 2.16$ & 0.003 \\
\hline Diastolic BP, mm Hg & $76.1 \pm 7.43$ & $76.74 \pm 4.87$ & $76.1 \pm 7.43$ & NS \\
\hline $\mathrm{GFR}, \mathrm{ml} / \mathrm{min}$ & $116.9 \pm 14.6$ & $116.67 \pm 24.77$ & $109.1 \pm 17.9$ & NS \\
\hline UAE, mg/day & $182.6 \pm 59.3$ & $124.48 \pm 31.14$ & $1,242.6 \pm 1,996.2$ & 0.001 \\
\hline
\end{tabular}

existed between intrarenal and orbital RI values in Group 2 ( $\mathrm{r}=0.475,0.285,0.363, \mathrm{p}<0.01$, respectively), but did not exist in Group 1 (table 6).

The effect of orbital RI on intrarenal RI was assessed by linear regression analysis. Orbital arterial RI values had a positive increase effect on intrarenal RI values (table 7).

Diabetic retinopathy was detected in 22 patients in Group 1 (Group 1a). There was no statistical difference in terms of clinical factors in either group (Group la, Group 1b). Intrarenal and orbital RI values (except CRA) in Group la patients were significantly higher than those in the Group $1 b$ patients.

In Group 2, 35 patients with diabetic retinopathy were detected (Group 2a). In Group 2a, age (60.8 \pm 10.5/53.3 \pm 8.8 years, $p=0.012$ ), duration of diabetes (11.1 \pm 4.6/7.22 \pm 4 years, $\mathrm{p}=0.004), \mathrm{HbAlc}(8.07 \pm 2.43 / 7.46$ $\pm 0.96, \mathrm{p}=0.038)$, mean renal RI $(0.71 \pm 0.06 / 0.68 \pm$ $0.05, \mathrm{p}=0.017)$, mean OA RI $(0.79 \pm 0.07 / 0.72 \pm 0.07$, $\mathrm{p}=0.002)$, mean CRA RI $(0.71 \pm 0.06 / 0.65 \pm 0.06$ $\mathrm{p}=0.005)$ and mean PCA RI $(0.75 \pm 0.05 / 0.71 \pm 0.06$, $\mathrm{p}=0.015)$ were statistically significant in the Group $2 \mathrm{~b}$ (tables 8, 9).

There is a statistically significant difference between Group 1a and Group 2a patients with retinopathy regarding age $(\mathrm{p}=0.001)$, GFR $(\mathrm{p}=0.001)$ and UAE $(\mathrm{p}=$ $0.003)$.

Intrarenal, OA and CRA RI values in Group 2a patients were significantly higher than in Group 1a. Only intrarenal RI values in Group $2 \mathrm{~b}$ patients were significantly higher in comparison to Group $1 \mathrm{~b}$ patients.
Table 4. Correlation between the RI values of intrarenal arteries and clinical characteristics

\begin{tabular}{lccc}
\hline & $\begin{array}{l}\text { All patients } \\
(\mathrm{n}=103)\end{array}$ & $\begin{array}{c}\text { Group 1 } \\
(\mathrm{n}=50)\end{array}$ & $\begin{array}{c}\text { Group 2 } \\
(\mathrm{n}=53)\end{array}$ \\
\hline Age & $0.351^{* *}$ & 0.088 & $0.323^{*}$ \\
GFR & $-0.451^{* *}$ & -0.102 & $-0.346^{*}$ \\
UAE & 0.177 & 0.083 & 0.076 \\
Diabetes duration & $0.499^{* *}$ & 0.056 & $0.362^{* *}$ \\
Systolic BP & 0.314 & 0.098 & -0.009 \\
Diastolic BP & 0.057 & 0.172 & 0.069 \\
HbA1c & 0.056 & 0.093 & 0.066 \\
\hline
\end{tabular}

Pearson's correlation analysis. ${ }^{*} \mathrm{p}<0.05 ;{ }^{* *} \mathrm{p}<0.01$.

\section{Discussion}

We showed that both intrarenal and orbital vascular resistance in diabetic patients were higher than healthy individuals, and a trend towards higher RI values was observed with renal disease. There is a correlation between orbital and intrarenal arterial RI values.

Doppler US provides an easily applicable and noninvasive method for investigating renal and ophthalmologic disease. RI has been used to evaluate changes in vascular resistance due to urinary obstruction and acute and chronic renal failure. Based on previous studies, renal RI values of normoalbuminuric DM patients have been shown to be significantly elevated; furthermore, a trend towards higher RI values has been observed when renal disease coexists $[16,17]$.

We used sonography to examine intrarenal and orbital hemodynamic changes noninvasively in patients 
Table 5. Correlation between the RI values of orbital arteries and clinical characteristics

\begin{tabular}{llllllll}
\hline & Age & GFR & UAE & Diabetes duration & Systolic BP & Diastolic BP & HbA1 \\
\hline OA RI & $0.343^{* *}$ & $-0.279^{*}$ & 0.123 & $0.365^{* *}$ & 0.134 & -0.004 \\
CRA RI & $0.272^{* *}$ & -0.182 & 0.057 & $0.339^{* *}$ & 0.120 & -0.089 \\
PCA RI & $0.195^{*}$ & $-0.347^{*}$ & -0.010 & $0.314^{* *}$ & 0.068 & -0.056 & 0.056 \\
\hline
\end{tabular}

Pearson's correlation analysis. ${ }^{*} \mathrm{p}<0.05 ;{ }^{* *} \mathrm{p}<0.01$

Table 6. Correlation between the RI values of renal and orbital arteries

\begin{tabular}{llll}
\hline & $\begin{array}{l}\text { All patient } \\
\text { renal RI }\end{array}$ & $\begin{array}{l}\text { Group 1 } \\
\text { renal RI }\end{array}$ & $\begin{array}{l}\text { Group 2 } \\
\text { renal RI }\end{array}$ \\
\hline OA RI & $0.421^{* *}$ & 0.181 & $0.475^{* *}$ \\
CRA RI & $0.285^{* *}$ & 0.159 & $0.285^{*}$ \\
PCA RI & $0.285^{* *}$ & 0.067 & $0.363^{* *}$ \\
\hline
\end{tabular}

${ }^{*} \mathrm{p}<0.05 ;{ }^{* *} \mathrm{p}<0.01$
Table 7. Effect of orbital arterial RI values on renal RI values

\begin{tabular}{llllll}
\hline & $\mathrm{B}$ & $\mathrm{SE}$ & $\beta$ & $\mathrm{t}$ & $\mathrm{p}$ \\
\hline Constant & 0.268 & 0.062 & & 4.324 & 0.001 \\
OA RI & 0.335 & 0.077 & 0.383 & 4.330 & $0.001^{*}$ \\
CRA RI & 0.131 & 0.068 & 0.112 & 1.230 & 0.221 \\
PCA RI & 0.084 & 0.090 & 0.131 & 1.453 & 0.149 \\
\hline
\end{tabular}

${ }^{*} \mathrm{p}<0.01$.

Table 8. Clinical characteristics of the diabetic patients with/without kidney disease

\begin{tabular}{|c|c|c|c|c|c|c|c|c|}
\hline & $\begin{array}{l}\text { Group 2a } \\
(\mathrm{n}=35)\end{array}$ & $\begin{array}{l}\text { Group 2b } \\
(\mathrm{n}=18)\end{array}$ & $\mathrm{p}$ & $\begin{array}{l}\text { Group 1a } \\
(\mathrm{n}=22)\end{array}$ & $\begin{array}{l}\text { Group 1b } \\
(\mathrm{n}=28)\end{array}$ & $\mathrm{p}$ & $\begin{array}{l}\text { Group } \\
1 \mathrm{a}-2 \mathrm{a} \\
\mathrm{p}\end{array}$ & $\begin{array}{l}\text { Group } \\
1 \mathrm{~b}-2 \mathrm{~b} \\
\mathrm{p}\end{array}$ \\
\hline Gender, male/female & $9 / 26$ & $8 / 10$ & NS & $11 / 11$ & $12 / 16$ & NS & NS & NS \\
\hline Age, years & $60.8 \pm 10.5$ & $53.3 \pm 8.8$ & 0.012 & $49.7 \pm 7.9$ & $51.8 \pm 8.7$ & NS & 0.001 & NS \\
\hline BMI & $31.5 \pm 6.8$ & $30.8 \pm 4.7$ & NS & $30.2 \pm 8.4$ & $31.2 \pm 5.2$ & NS & NS & NS \\
\hline Systolic BP, mm Hg & $130.4 \pm 15.1$ & $127.8 \pm 17.7$ & NS & $130 \pm 13.8$ & $131.4 \pm 15.5$ & NS & NS & NS \\
\hline Diastolic BP, mm Hg & $74.9 \pm 7.6$ & $75.56 \pm 9.2$ & NS & $76.6 \pm 6.7$ & $76.1 \pm 7.3$ & NS & NS & NS \\
\hline $\mathrm{GFR}, \mathrm{ml} / \mathrm{min}$ & $104.54 \pm 14.59$ & $114.59 \pm 19.15$ & 0.021 & $120.3 \pm 29.5$ & $123.9 \pm 20.5$ & NS & 0.001 & 0.001 \\
\hline UAE, mg/day & $1,618.6 \pm 257$ & $699.8 \pm 622$ & NS & $185 \pm 61.3$ & $178 \pm 60.6$ & NS & 0.003 & 0.001 \\
\hline
\end{tabular}

Group a: with diabetic retinopathy; Group b: no diabetic retinopathy.

with DM. We showed that renal vascular resistance in diabetic patients is higher than in healthy individuals. RI is significantly increased in CKD patients with diabetes compared to similar patients without CKD.

Pearce et al. [18] showed that in patients with DM and diabetic nephropathy (DN), the RI index was significantly affected by GFR, proteinuria and mean blood pressure.
The relationship between the RI values and GFR in DN patients showed a negative correlation coefficient. Nosadini et al. [19] showed a high level of correlation between GFR and intrarenal RI in clinical DN.

In the present study, factors affecting the RI values were examined in patients with DM. The relationship between the intrarenal artery RI values and GFR in Group 
Table 9. Renal and orbital arterial RI values of diabetic patients with/without kidney disease

\begin{tabular}{|c|c|c|c|c|c|c|c|c|}
\hline & \multicolumn{3}{|c|}{ Group $2(n=53)$} & \multicolumn{3}{|c|}{ Group $1(n=50)$} & \multirow{2}{*}{$\begin{array}{l}\text { Group } \\
1 \mathrm{a}-2 \mathrm{a} \\
\mathrm{p}\end{array}$} & \multirow{2}{*}{$\begin{array}{l}\text { Group } \\
1 \mathrm{~b}-2 \mathrm{~b} \\
\mathrm{p}\end{array}$} \\
\hline & $\begin{array}{l}\text { Group 2a } \\
(\mathrm{n}=35)\end{array}$ & $\begin{array}{l}\text { Group 2b } \\
(\mathrm{n}=18)\end{array}$ & $\mathrm{p}$ & $\begin{array}{l}\text { Group 1a } \\
(\mathrm{n}=22)\end{array}$ & $\begin{array}{l}\text { Group 1b } \\
(\mathrm{n}=28)\end{array}$ & $\mathrm{p}$ & & \\
\hline Renal RI & $0.71 \pm 0.06$ & $0.68 \pm 0.05$ & $0.017^{*}$ & $0.69 \pm 0.05$ & $0.63 \pm 0.05$ & 0.001 & $0.048^{*}$ & $0.003^{* *}$ \\
\hline OA RI & $0.79 \pm 0.07$ & $0.72 \pm 0.07$ & $0.002^{* *}$ & $0.75 \pm 0.06$ & $0.71 \pm 0.06$ & 0.020 & $0.031^{*}$ & NS \\
\hline CRA RI & $0.71 \pm 0.06$ & $0.65 \pm 0.06$ & $0.005^{* *}$ & $0.67 \pm 0.07$ & $0.65 \pm 0.07$ & NS & $0.042^{*}$ & NS \\
\hline
\end{tabular}

Group a: with diabetic retinopathy; Group b: no diabetic retinopathy. ${ }^{*} \mathrm{p}<0.05 ;{ }^{* *} \mathrm{p}<0.01$.

2 showed a negative correlation coefficient of $r=-0.346$, $\mathrm{p}=0.023$. The relationship between intrarenal RI values and age in Group 2 showed a positive correlation coefficient of $\mathrm{r}=-0.323, \mathrm{p}=0.023$. Ishimura et al. [10] reported a relationship between increased RI values and age.

Diabetes is a strong risk factor for arteriosclerosis and advanced arteriosclerosis occurs with increasing age, i.e. a long duration of diabetes [20-22]. The decline in GFR in type 2 diabetes is in part due to generalized increase in arteriosclerosis. When we regard mechanisms by which RI of intrarenal arteries increase, arterio-arteriolosclerosis also could play an important role [23].

There have been many efforts for earlier diagnosis and management of DN. Microalbuminuria is widely accepted as the first clinical evidence of DN [24]. However, the prevalence of patients with type 2 diabetes and renal insufficiency in the absence of both albuminuria and retinopathy is about $30 \%$ [25]. Thus, there is a need for additional markers, either alone or in combination with microalbuminuria, for the early identification of individuals susceptible to clinical nephropathy.

Doppler US has provided an easily applicable and noninvasive method for investigating renal hemodynamics. Elevated RI might be observed in type 2 diabetic patients even in a normoalbuminuric state. Abd El Ghaffar et al. [26] showed that all renal Doppler indices were significantly higher in children with type $1 \mathrm{DM}$ ( $\mathrm{p} \leq 0.01$ ). No correlation was noted to microalbuminuria, HbAlc or duration of diabetes. In these patients, renal Doppler assessment might diagnose DN at a prealbuminuric stage. Thus, RI may be important for early diagnosis and follow-up of DN.

Nephropathy and retinopathy are serious microvascular complications of DM. Early functional and structural abnormalities may be seen a few years after onset of the disease. In patients with type 2 diabetes of less than 5 years' duration, the prevalence of retinopathy is approximately $25-40 \%$. In addition, it has been demonstrated that for every 5 -year increase in diabetes duration, the risk for diabetic retinopathy increases 1.89-fold [27].

Among those with very early diabetes (diagnosis within 6-12 months from the onset of diabetes), almost $13 \%$ have diabetic retinopathy. Diabetic retinopathy and DN frequently coexist. Type 2 diabetics with marked proteinuria and retinopathy most likely have DN. However, lack of retinopathy in type 2 diabetes does not preclude DN, which remains the most likely diagnosis [28]. Twenty to $45 \%$ of type 2 diabetic patients with proteinuria do not show retinal diabetic lesions. Lack of retinopathy is also associated with a better renal prognosis $[29,30]$.

There are several other risk factors independently associated with retinopathy that can contribute to developing diabetic retinopathy: duration of diabetes, glycemic control, systolic blood pressure and urinary albumin concentration [28].

In Group 2 patients, the mean duration of diabetes was $8.26 \pm 4.69$ years. Thirty-five patients had diabetic retinopathy. The mean duration of the diabetes, age and HbAlc levels were risk factors for diabetic retinopathy in Group 2, but not for Group 1.

In diabetic retinopathy, orbital arterial velocity decreases due to fibrosis in the developing vascular structures. Disturbance of retinal hemodynamics is an accepted surrogate marker of early diabetic retinopathy $[31,32]$. Using Doppler sonography, Kawagishi et al. [33] found an increase in resistance index in the CRA of patients with type 1 diabetes before the development of retinopathy. It was hypothesized that the increased resistance index resulted from a combination of increased vessel rigidity and peripheral vascular resistance. 
Arai et al. [34] showed that the RI of orbital arterial flow was increased in patients with DM and further increased in the presence of retinopathy. Increased resistance in the peripheral orbital vascular bed contributes to diabetic retinopathy, and this change is present before the appearance of overt diabetic retinopathy. Tamaki et al. [35] suggest that RI is significantly higher in diabetics $(0.77 \pm 0.04$ in patients without retinopathy, $0.77 \pm 0.08$ in patients with background retinopathy and $0.78 \pm 0.08$ in patients with preproliferative or proliferative retinopathy) than normal subjects. This in turn is associated with a pathological increase in choroidal vascular resistance and/or a decrease in the diameter of the OA.

The RI values of diabetic patients and normal subjects differ significantly. RI values were found to increase along with the presence of retinopathy. These results suggest that diabetic patients with no retinopathy display altered orbital hemodynamics. Doppler ultrasound may be a method for evaluation of vascular hemodynamics of retinal vessels in DM patients without background retinopathy, with background retinopathy and with proliferative retinopathy.

Intrarenal arteriosclerosis is an independent risk factor for increased intrarenal resistance index. Ohta et al. [36] evaluated the relationship between RI and pulse wave velocity, which reflects atherosclerosis, and showed that increased RI of renal arteries is associated with the severity of systemic atherosclerosis. On the other hand, RI correlates with extrarenal markers of vascular stiffness, such as intima-media thickness of the femoral and carotid arteries. Their results indicate that the increased $\mathrm{RI}$ of the renal arteries is associated with the severity of systemic atherosclerosis [10].

In our study, both the renal and orbital RI values of DM patients were shown to be significantly elevated. Further, a trend towards higher RI values was observed with renal disease. We have demonstrated the relationship be- tween renal and ophthalmic arterial RI. Retinal microvascular abnormalities are associated with renal dysfunction, suggesting that common systemic microvascular processes may underlie the development of microvascular damage in eyes and kidneys. Doppler US provides information about intrarenal and orbital vasculature. Therefore, when DM is diagnosed, orbital and renal RI values should be measured by Doppler US to predict renal and orbital complications early.

Normal ranges for RI are reported to be between 0.58 and 0.68 in normal kidneys. An RI of 0.70 or higher is predictive for an unfavorable outcome in patients with chronic nephropathies [37]. The mean OA, CRA and PCA RI was $0.68 \pm 0.06,0.63 \pm 0.09$ and $(0.67 \pm 0.07)$ in the control group. Orbital arterial RI values were found to be higher in diabetics with and without kidney disease compared to the control group. Intrarenal RI is an independent risk factor for progression of CKD. Further study is required to determine whether orbital artery RI can be a predicting factor for orbital complications.

\section{Conclusion}

We showed that both intrarenal and orbital vascular resistance in diabetic patients are higher than in healthy individuals, as well as that a trend towards higher RI values is observed with renal disease. There is a correlation between renal and orbital arterial RI values in diabetic patients with CKD. Orbital arterial RI values have a positive increase effect on renal RI values.

Doppler US allows rapid, noninvasive evaluation of the intrarenal and orbital hemodynamic abnormalities. RI may be useful as one of the markers for early diagnosis and follow-up of DN and retinopathy. Therefore, when $\mathrm{DM}$ is diagnosed, RI values should be measured by Doppler US.

\section{References}

1 Rumack C, Wilson S, Charboneau JW: Diagnostic Ultrasound: 2-Volume Set, ed 3. St. Louis, Elsevier Mosby, 2005.

-2 Yura T, Takamitsu Y, Yuasa S, Miki S, et al: Total and split renal function assessed by ultrasound Doppler techniques. Nephron 1991;58:37-41.

-3 Guven D, Ozdemir H, Hasanreisoglu B: Hemodynamic alterations in diabetic retinopathy. Ophthalmology 1996;103:1245-1249.
-4 Halpern EJ, Merton DA, Forsberg F: Effect of distal resistance on Doppler US flow patterns. Radiology 1998;206:761-766.

5 Bude RO, Rubin JM: Relationship between the resistive index and vascular compliance and resistance. Radiology 1999;211:411-417.

-6 MacIsaac RJ, Panagiotopoulos S, McNeil KJ, Smith TJ, et al: Is nonalbuminuric renal insufficiency in type 2 diabetes related to an increase in intrarenal vascular disease? Diabetes Care 2006;29:1560-1566.

\footnotetext{
7 Goebel W, Lieb WE, Ho A, Sergott RC, et al: Color Doppler imaging: a new technique to assess orbital blood flow in patients with diabetic retinopathy. Invest Ophthalmol Vis Sci 1995;36:864-870.

8 Schwartz MM, Lewis EJ, Leonard-Martin T, Lewis JB, Batlle D: Renal pathology patterns in type II diabetes mellitus: relationship with retinopathy. The Collaborative Study Group. Nephrol Dial Transplant 1998;13:2547-2552.
} 
\9 Wong TY, Coresh J, Klein R, Muntner P, Couper DJ, Sharrett AR, Klein BE, Heiss G, Hubbard LD, Duncan BB: Retinal microvascular abnormalities and renal dysfunction: the atherosclerosis risk in communities study. J Am Soc Nephrol 2004;15:2469-2476.

-10 Ishimura E, Nishizawa Y, Kawagishi T, Okuno $\mathrm{Y}$, et al: Intrarenal hemodynamic abnormalities in diabetic nephropathy measured by duplex Doppler sonography. Kidney Int 1997;51:1920-1927.

- 11 American Diabetes Association: Diagnosis and classification of diabetes mellitus. Diabetes Care 2010;33(suppl 1):S62.

12 Levey AS, Bosch JP, Lewis JB, Greene T, Rogers N, Roth D: A more accurate method to estimate glomerular filtration rate from serum creatinine: a new prediction equation. Modification of Diet in Renal Disease Study Group. Ann Intern Med 1999;130:461-470.

13 National Kidney Foundation: K/DOQI clinical practice guidelines for chronic kidney disease: evaluation, classification, and stratification. Am J Kidney Dis 2002;39(suppl 1):S1-S266.

14 Fukuda M: Classification and treatment of diabetic retinopathy. Diabetes Res Clin Pract 1994;24(suppl):S171-S176.

15 Guidelines Commitee: 2003 European Society of Hypertension - 2003 European Society of Cardiology guidelines for the management of arterial hypertension. J Hypertens 2003;21:1011-1053.

16 Derchi LE, Martinoli C, Saffioti S, Pontremoli R, De Micheli A, Bordone C: Ultrasonographic imaging and Doppler analysis of renal changes in non-insulin dependent diabetes mellitus. Acad Radiol 1994;1:100-105.

17 Sauvain JL, Bourscheid D, Girardot MN, Pierrat V, Sol F, Ory JP: Echo Doppler renal, index resistance de Pourcelot et nephropathie diabetique: interet et signification. Rev Int Med 1994;6:151-158.

18 Pearce JD, Edwards MS, Cravan TE, English WP, Mondi MM, Reavis SW, Hansen KJ: Renal duplex parameters, blood pressure, and renal function in elderly people. Am J Kidney Di 2005;45:842-850.
9 Nosadini R, Velussi M, Brocco E, Abaterusso C, Carraro A, Piarulli F, Morgia G, Satta A, Faedda R, Abhyankar A, Luthman H, Tonolo G: Increased renal arterial resistance predicts the course of renal function in type 2 diabetes with microalbuminuria. Diabetes 2006;55:234-239.

20 Yamasaki Y, Kawamori R, Matsushima H, Nishizawa H, Kodama M, Kajimoto Y, Morishima T, Kamada T: Atherosclerosis in carotid artery of young IDDM patients monitored by ultrasound high-resolution B-mode imaging. Diabetes 1994;43:634-639.

21 Hetinstall RH: Hypertension II. Essential hypertension; in Heptinstall RH(ed): Pathology of the Kidney, ed 3. Boston, Little Brown and Company, 1983, pp 181-246.

22 Garcia MJ, McNamara PM, Gorodon T, Kannell WB: Morbidity and mortality in diabetics in the Framingham population: sixteenyear follow-up study. Diabetes 1974;23:105111.

23 Ikee R, Kobayashi S, Hemmi N, Imakiire T, Kikuchi Y, Moriya H, Suzuki S, Miura S: Correlation between the resistive index by Doppler ultrasound and kidney function and histology. Am J Kidney Dis 2005;46: 603-609.

24 Mogensen CE, Christensen CK, Vittinghus E: The stages in diabetic renal disease. With emphasis on the stage of incipient diabetic nephropathy. Diabetes 1983;32(suppl 2):6478.

25 Kramer HJ, Nguyen QD, Curhan G, Hsu CY: Renal insufficiency in the absence of albuminuria and retinopathy among adults with type 2 diabetes mellitus. JAMA 2003;289: 3273-3277.

26 Abd El Ghaffar S, El Kaffas K, Hegazy R, Mostafa M: Renal Doppler indices in diabetic children with insulin resistance syndrome. Pediatr Diabetes 2010;11:479-486.

-27 Rema M, Premkumar S, Anitha B, Deepa R, Pradeepa R, Mohan V: Prevalence of diabetic retinopathy in urban India: the Chennai Urban Rural Epidemiology Study (CURES) Eye Study, I. Invest Ophthalmol Vis Sci 2005; 46:2328-2333.

28 Jawa A, Kcomt J, Fonseca VA: Diabetic nephropathy and retinopathy. Med Clin North Am 2004;88:1001-1036.
29 Parving HH, Gall MA, Skott P, Jorgensen HE, Lokkegaard H, Jorgensen F, et al: Prevalence and causes of albuminuria in non-insulin-dependent diabetic patients. Kidney Int 1992;41:758-762.

-30 Christensen PK, Larsen S, Horn T, Olsen S, Parving HH: Causes of albuminuria in patients with type 2 diabetes without diabetic retinopathy. Kidney Int 2000;58:1719-1731.

- 31 Bursell SE, Clermont AC, Kinsley BT, Simonson DC, Aiello LM, Wolpert HA: Retinal blood flow changes in patients with insulin-dependent diabetes mellitus and no diabetic retinopathy. Invest Ophthalmol Vis Sci 1996;37:886-897.

- 32 Yoshida A, Feke GT, Morales-Stoppello J, Collas GD, Goger DG, McMeel JW: Retinal blood flow alterations during progression of diabetic retinopathy. Arch Ophthalmol 1983; 101:225 -227.

33 Kawagishi T, Nishizawa Y, Emoto M, Konishi T, Maekawa K, Hagiwara S, Okuno Y, Inada $\mathrm{H}$, Isshiki $\mathrm{G}$, Morii $\mathrm{H}$ : Impaired retinal artery blood flow in IDDM patients before clinical manifestations of diabetic retinopathy. Diabetes Care 1995;18:1544-1549.

34 Arai T, Numata K, Tanaka K, Kiba T, Kawasaki S, Saito T, Satoh S, Sekihara H: Ocular arterial flow hemodynamics in patients with diabetes mellitus. J Ultrasound Med 1998;17: 675-681.

35 Tamaki Y, Nagahara M, et al: Blood velocity in the ophthalmic artery detrmined by color Doppler imaging in normal subjects and diabetics. Jpn J Ophthalmol 1993;37:385-392.

- 36 Ohta Y, Fujii K, Arima H, Matsumura K, Tsuchihashi T, Tokumoto M, Tsuruya K, Kanai $\mathrm{H}$, Iwase $M$, Hirakata $\mathrm{H}$, Iida $\mathrm{M}$ : Increased renal resistive index in atherosclerosis and diabetic nephropathy assessed by Doppler sonography. J Hypertens 2005;23: 1905-1911.

37 Parolini C, Noce A, Staffolani E, Giarrizzo GF, Costanzi S, Splendiani G: Renal resistive index and long-term outcome in chronic nephropathies. Radiology 2009;252:888-896. 